\title{
Review Article \\ Potential of Mushroom Compounds as Immunomodulators in Cancer Immunotherapy: A Review
}

\author{
Peter Amwoga Ayeka (10 \\ Department of Biological Sciences, Faculty of Science, Egerton University, P.O. Box 536-20115, Egerton, Kenya \\ Correspondence should be addressed to Peter Amwoga Ayeka; amwogahpeter@yahoo.com
}

Received 25 October 2017; Revised 12 February 2018; Accepted 15 March 2018; Published 22 April 2018

Academic Editor: Célia Cabral

Copyright (C) 2018 Peter Amwoga Ayeka. This is an open access article distributed under the Creative Commons Attribution License, which permits unrestricted use, distribution, and reproduction in any medium, provided the original work is properly cited.

\begin{abstract}
Since time immemorial, plants and their compounds have been used in the treatment and management of various ailments. Currently, most of conventional drugs used for treatment of diseases are either directly or indirectly obtained from plant sources. The fungal group of plants is of significance, which not only provides food directly to man but also has been source of important drugs. For instance, commonly used antibiotics are derived from fungi. Fungi have also been utilized in the food industry, baking, and alcohol production. Apart from the economic importance of the microfungi, macrofungi have been utilized directly as food, which is usually got from their fruiting bodies, commonly known as mushrooms. Due to their richness in proteins, minerals, and other nutrients, mushrooms have also been associated with boosting the immune system. This makes mushrooms an important food source, especially for vegetarians and immunosuppressed individuals including the HIV/AIDS persons. In complementary and alternative medicines (CAMs), mushrooms are increasingly being accepted for treatment of various diseases. Mushrooms have been shown to have the ability to stimulate the immune system, modulate humoral and cellular immunity, and potentiate antimutagenic and antitumorigenic activity, as well as rejuvenating the immune system weakened by radiotherapy and chemotherapy in cancer treatment. This potential of mushrooms, therefore, qualifies them as candidates for immunomodulation and immunotherapy in cancer and other diseases' treatment. However, a critical review on mushroom's immune modulating potential in cancer has not been sufficiently addressed. This review puts forward insights into the immune activities of mushroom associated with anticancer activities.
\end{abstract}

\section{Introduction}

Humanity continues to suffer the scourge of cancer, a disease that is associated with uncontrolled cell growth. In 2013, it was reported to be among the leading causes of death, second to cardiovascular diseases. It is estimated that death due to cancer will rise to thirteen million in 2030 [1-3]. The fight against cancer has intensified in the past decades with multidirectional approach including behavioral and dietary change, chemotherapy, radiotherapy, surgery, and recently immunotherapy. Unfortunately, these approaches are not void of serious side effects spanning from recurrence and weakened immune system to reduced quality of life (QoL) of patients. This has raffled scientists, leading to concerted efforts of finding better therapies that, apart from managing the cancerous cells, boost the immune system to fight cancer and other diseases [4]. Among these therapies, complementary and alternative medicine (CAM) has been fronted as an alternative due to its potential of holistic treatment including augmenting the immune system. Many CAMs are plantderived, including algae and mushrooms that have been used widely in many parts of the world, where they are regarded as biological response modifiers (BRMs) and immunoceuticals [5]. Mushrooms are the spore-producing reproductive structures of fungi. Ancient classification placed fungi in plant kingdom, but current classification recognizes fungi as an independent group of organisms under the kingdom Mycota, basically due to possession of chitin within their cell walls. Mushrooms are the fleshy, spore-bearing fruiting body of a fungus, typically produced above ground on soil or on its substrate, mainly by the Basidiomycota and Ascomycota group. Although in wild mushrooms are seasonal and can 
TABLE 1: Bioactive compounds from mushrooms with anticancer activity.

\begin{tabular}{lccc}
\hline Mushroom & Cancer & Common name & Compound/extract \\
\hline Agaricus bisporus & Breast, colorectal & White button & $\begin{array}{c}\text { Polysaccharides, lectin } \\
\text { Ganoderma polysaccharides, } \\
\text { polysaccharide-peptides }\end{array}$ \\
Ganoderma lucidum & Breast, colorectal, cervical, prostate, liver, and lung & Lingzhi/reishi & Krestin, PSK, PSP \\
Coriolus versicolor & Breast, colorectal, and skin & Yun Zhi & Lentinan \\
Lentinus edodes & Cervical/ovarian, gastric, and skin & Shiitake & Grifolan, Maitake D fraction \\
Grifola frondosa & Breast and bladder & Maitake & Agaricus polysaccharides \\
Agaricus blazei & Leukemia, hematological, stomach, and lung & Brazilian & Pleuran \\
P. tuber-regium & Liver & King tuber & Winter \\
Flammulina velutipes & Skin & & Flammulin \\
\hline
\end{tabular}

Modified from Roupas et al. (2012).

be collected and used, they can be domesticated through spore or tissue culture in the laboratories. There are over 14,000 mushroom species but only about 3000 are edible, with approximately 700 exhibiting medicinal properties and $1 \%$ being poisonous [6]. For many years, mushrooms have been associated with nutritional and medicinal properties including immune modulation and antitumor properties [611]. Edible mushrooms, according to research, are believed to strengthen the immune system by exerting their effects on cellular activities, secondary production of chemical compounds that boost the immune system, and helping treat diseases and restore cell immunity destroyed by radiation and chemotherapy, and this is linked majorly to $\beta$-glucans $[12,13]$.

A key, frequently reported protective mechanism exerted by mushrooms against cancer is the capacity to stimulate the immune system response, where beta-glucan, a water-soluble polysaccharide, activates immune cells and proteins and macrophages, $\mathrm{T}$ cells, natural killer cells, and cytokines that attack tumor cells [10]. White button mushroom Agaricus bisporus is an example of dietary mushrooms; apart from having bioactive antioxidants and anticarcinogenic substances, these bioactive compounds also alter aromatase enzyme activity. This enzyme is involved in the conversion of androgens to proliferative estrogenic intermediates which are closely linked to breast cancer development $[14,15]$. Furthermore, nonpolysaccharide constituents in species like Shiitake and Oyster mushrooms have biological activity against murine skin cancer and human prostate carcinoma cells [16]. The antitumor and immunomodulation activity of mushroom is exhibited by both crude fungal extracts and pure compounds. The polysaccharide fraction that is mainly composed of $\beta$ glucans present in the cell walls is responsible for immune modulating effects in a number of ways including activating phagocytic activity and production of reactive oxygen intermediates, inflammatory mediators, and cytokines production $[7,10,17]$.

\section{Selected Medicinal Mushrooms and Their Anticancer Activity}

Mushrooms can either be edible, medicinal, or poisonous. Many mushroom species, either edible or poisonous, contain bioactive compounds that are of significance to human health.

Mushroom cell walls contain two important compounds, chitin and $\beta$-glucans. Of these two, $\beta$-glucans $\beta(1 \rightarrow 3)$, $\beta(1 \rightarrow 4)$, and $\beta(1 \rightarrow 6)$ make mushroom of significance in health and treatment of various diseases [18-20]. In addition to these compounds, there are other important components in mushrooms. They include polysaccharides, polysaccharide-protein complexes, agaritine, ergosterol, selenium, polyphenols, and terpenoids. Apart from therapeutic properties associated with these compounds, they are generally regarded as biological response modifiers (BRMs). Both in vitro and in vivo experiments support the therapeutic activities of mushroom compounds. These compounds modulate the immune system to fight tumors and other diseases. These include augmenting the immune system through stimulating lymphocytes, NK cells, and macrophages, enhancing cytokine production, inhibiting proliferation of cancer cells, promoting apoptosis, and blocking angiogenesis, in addition to being cytotoxic to cancer cells $[21,22]$. These compounds come in contact with intestinal cells, the frontline of intestinal immune system which interacts with the antigens, thereby playing a role in intestinal immune response and inducing inflammatory response if necessary [23]. Mushroom-derived polysaccharides and polysaccharide-protein complexes are considered as one of the major sources of therapeutic agents for immunomodulatory and antitumor properties [21, 24]. More than 50 mushroom species have yielded potential immunoceuticals with immunomodulatory and antitumor effects in vitro and in vivo and also in human cancers. They include lectins, polysaccharides, polysaccharides-peptides, polysaccharide-protein complexes like lentinan, schizophyllan, polysaccharide- $K$, polysaccharide $P$, active hexose correlated compounds (AHCC), and Maitake D fraction. These compounds are derived from Ganoderma lucidum, G. tsugae, Schizophyllum commune, Sparassis crispa, Pleurotus tuberregium, $P$. rhinoceros, Trametes robiniophila Murill, Coriolus versicolor, Lentinus edodes, Grifola frondosa, and Flammulina velutipes, among others [17]. These mushrooms are associated with the treatment of various cancers including breast, colorectal, cervical, skin, liver, ovarian, bladder, prostate, gastric, skin, lung, leukemia, and stomach cancers (Table 1). 


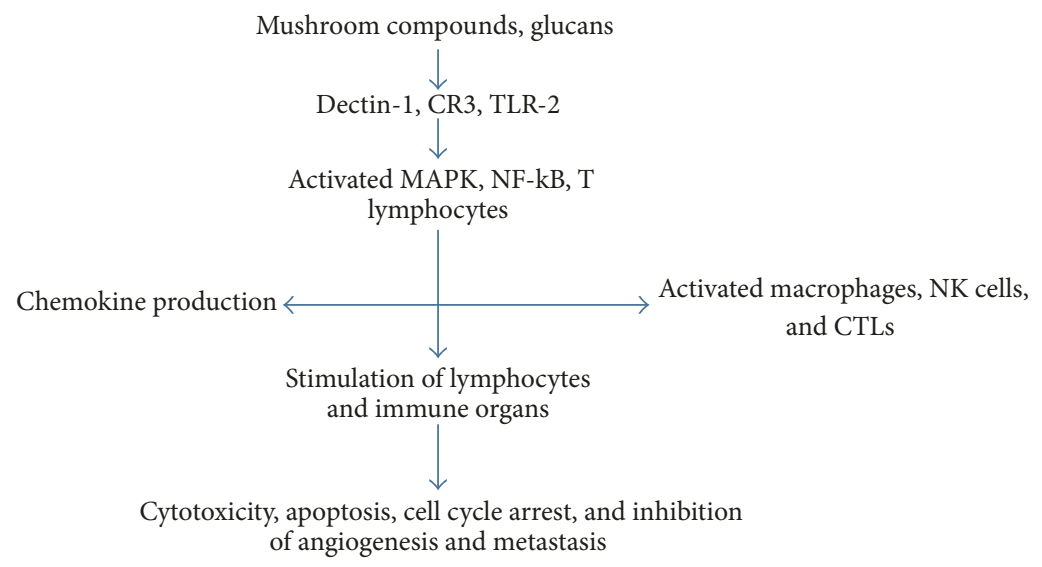

Figure 1: Probable immunomodulation mechanism of action of mushroom glucans. They utilize Dectin-1, CR3, and TLR-2 leading to activation and signal transduction of T lymphocytes, MAPK, and NF-kB, in turn leading to chemokine production and activation and stimulation of lymphocytes, macrophages, and NK cells, which results in inhibition of cancer proliferation through either direct toxicity, apoptosis, and cancer cell cycle arrest or hindering angiogenesis and metastasis of cancer cells.

Mushroom compounds utilize different mechanisms to modulate immunity system in cancer treatment. For instance, water extracts of Agaricus blazei Murill (AbM) fruiting bodies induce production of TNF-alpha, IL-8, and NO- [25]; it is low molecular weight polysaccharides that suppress tumor growth and angiogenesis in vivo [26], and they contain agaritine and ergosterol which are capable of inducing apoptosis in leukemia cells and inhibit tumor-induced angiogenesis [27, 28]. Ganoderma lucidum polysaccharides and triterpenoids are potent inhibitors of tumor growth in vitro and in vivo [14]. Furthermore, extracts of G. lucidum and G. tsugae are able to inhibit growth of colorectal cancer cells in vitro [29]. Schizophyllan, from Schizophyllan commune, a $\beta(1-3)$ and $\beta(1-6)$ D-glucan, is less effective against gastric cancer but increases survival of patients with head and neck cancer. In cervical cancer, it prolongs survival and time to recurrence for stage II, and it is more effective when injected directly to the cancer mass [30], suggesting a direct cytotoxicity effect to tumor cells. There is also a remarked increase in monocytes and granulocytes in blood and spleen, leading to production of IL- 6 and IL- 8 after use of Cauliflower mushroom (Sparassis crispa), suggesting that it has immunomodulatory properties [31]. Other mushrooms like $P$. tuber-regium and $P$. rhinoceros polysaccharides have antitumor effects, where they are able to induce expression and proliferation of NK cells, macrophages, and Thelper cells in mice [32-34] and Trametes robiniophila Murrill (Huaier), an officinal fungus in China, has been applied in TCM for approximately 1600 years [35] and its proteoglycans display apoptosis, antiangiogenesis, drug resistance reversal, antimetastasis, and system immune activation. Table 1 highlights selected mushrooms studied in various cancers.

\section{Mechanism of Modulating the Immune System by Anticancer Mushroom Compounds}

Mushroom compounds are known to fight cancers through modulating both innate (nonspecific) and adaptive (specific) immune systems. The response of an immune system after invasion by antigens heavily relies on interaction between host pattern recognition receptors (PRRs) and pathogen associated molecular patterns (PAMPs). PRRs initiate innate immunity through pathogen recognition, while toll-like receptors (TLRs) initiate signaling pathways that coordinate innate immunity and trigger adaptive immunity against various pathogens [56]. Mushroom cell walls have compounds, especially $\beta$-glucans, which are thought to be a major PAMP involved in initiating an immune response. The receptors of $\beta$-glucans, Dectin-1, are expressed on dendritic cells, macrophages, neutrophils, and monocytes $[57,58]$. Binding of Dectin- 1 and $\beta$-glucans leads to signal transduction which in turn activates $\mathrm{T}$ cells, mitogen activated protein kinases (MAPK), and nuclear factor kappa B (NF-kB), resulting in cytokine production [59, 60]. More so, mushroom compounds are recognized by the PRR, by utilizing the Dectin-1, toll-like receptor 2 (TLR-2), and the complement receptor 3 (CR3). PAMP binds to TLR2 initiating the adaptive immunity and PAMP-PRR on monocytes, dendritic cells, granulocytes, and NK cells of the innate immune system [61-65] leading to activation of immune cells, cytokine production, and expression of adhesion molecules $[66,67]$, as illustrated in Figure 1.

In addition, glucans, which are pharmacologically important compounds of mushrooms, are resistant to acid and therefore they are able to pass through the stomach to the duodenum, where they interact with receptors, activating them to produce lysozyme, reactive oxygen radicals, and nitrogen oxides. These in turn stimulate the production of cytokines that activate phagocytes and leukocytes, leading to local or systemic immunity [68-70].

The efficiency of beta-glucans to activate leukocytes is dependent not only on their conformation but also on solubility in water, molecular weight, and degree of substitution and branching. Their pharmacological activity can be linked to interaction with specific $\beta$-glucopyranose receptors on leukocytes. This interaction activates leukocytes, which in 
turn stimulate phagocytosis, cytotoxicity, and production of cytokines by leukocytes $[71,72]$.

\section{Effects of Mushroom Compounds on Cytokine Production}

Mushroom compounds exert their immune modulating properties through a variety of molecular mechanisms. Some upregulate genes which leads to production of antiinflammatory and anticancer cytokines. Studies with mushroom compounds have shown that a number of genes and cytokines are variously affected following in vitro and in vivo treatments. Cytokines are the messengers of the immune system and are either proteins or glycoproteins, secreted by immune cells, to regulate innate and adaptive immune system [6]. Following an oral uptake of mushrooms/mushroom compounds, intestinal immune factors are activated, that is, dendritic cells and macrophages that secrete cytokines that initiate local or systemic immunity. Intestinal epithelial cells are also stimulated to secrete IL-7, an important cytokine in cancer immunotherapy $[73,74]$.

Incubation of promonocytic THP-1 cells with Agaricus blazei Murill extract upregulates many genes that are associated with anticancer chemokines, leading to secretion of a number of cytokines such as IL-23 $\alpha$ subunit in the IL-12 family, IL-1 $\beta$, monocyte chemoattractant protein-1 (MCP-1), granulocyte colony stimulating factor (G-CSF), and tumor necrosis factor-alpha (TNF- $\alpha)[27,36]$. Furthermore, Volman et al. [75] showed that Agaricus bisporus fruit bodies, caps, and stipe increase TNF- $\alpha$ production by bone marrow derived macrophages (BMM).

Ganoderma lucidum, on the other hand, is longevitypromoting tonic herb and the biological activities, especially antitumor and immunomodulatory properties, include stimulating $\mathrm{T}$ cells and inflammatory response by expression and production of chemokines including IL-1, IL-2, IL-6, TNF$\alpha$, and interferon-gamma (IFN- $\gamma$ ) $[4,41,42]$. Grifolan from Grifola frondosa promotes macrophage activities by increasing IL-1, IL-6, and IL-8 production, ultimately activating and increasing the number of leukocytes $[45-47,76]$. Other compounds from mushrooms such as polysaccharide peptide (PSP), polysaccharide (PSK), and lentinan provoke in vitro secretion of varied cytokines, namely, IL-1, IL-2, IL-6, IL-8, TNF, and interferons [49].

In addition, Bittencourt et al. [52] demonstrated that $\alpha$-glucan from Pseudallescheria boydii stimulates in vitro secretion of TNF- $\alpha$ and IL-12. The increased secretion of IL-12 indicates a polarization of naïve T cells into T helper (Th) type 1 skewed responses which are important in fighting cancer cells $[37,77]$. The extract from Sparassis crispa stimulates splenocytes to secrete cytokines in mice and this is triggered by granulocyte macrophage colony stimulating factor (GMCSF) and Dectin-1, which is $\beta$-glucan receptor [48].

\section{Effect of Mushroom Compounds on Immune Cells}

Mushroom compounds injected directly into tumor cells or taken orally activate the immune cells to initiate a cell mediated or direct cytotoxicity on tumor cells after being recognized by pathogen recognition receptors. Compounds like lentinan increase the production of cytotoxic T lymphocytes and macrophages and also induce nonspecific immune responses [49]. Pleurotus tuber-regium and P. rhinoceros extracts confer antitumor effects by promoting maturation of lymphocytes and NK cells and increasing macrophages proliferation, T helper cells, and CD4/CD8 ratio and population, which is accompanied by increase in weight and size of spleen, and this increase is attributed to the higher numbers of monocytes and granulocytes among other immune cells $[32-34,78]$. Therefore, consumption of mushroom compounds initiates innate and adaptive immunity by enhancing immune-surveillance against cancer by involving monocytes, macrophages, NK cells, and B cells, CTLs secretion antitumor related cytokines and activation of immune organs, getting rid of cancers, and strengthening the weakened immune system $[64,65]$. These actions by mushroom compounds lead to cancer cell apoptosis, cell cycle arrest, and prevention of angiogenesis and metastasis.

\section{Inhibition of Proliferation and Cell Cycle Arrest by Mushroom Compounds}

Various cancers, including hematological cancers in mouse and leukemia in humans, among other tumors are inhibited by mushrooms $[27,79]$. Their mechanism of action is varied and is believed to include induction of apoptosis and upregulation of apoptosis inducing genes as well as arrest of cell division in vitro and in vivo $[38,39]$.

Mushroom compounds injected into tumor mass lead to apoptosis of the cells at different stages of cell cycle to curb tumor cell proliferation. For instance, lentinan and lectins from Shiitake are directly cytotoxic and cytostatic to MCF-7 breast cancer cells $[53,54]$. They also show antiinflammatory effect by reducing levels of neoangiogenic and granulocyte-chemoattractant factor IL-8 and increase infiltration of cytotoxic $\mathrm{T}$ cells by reducing intratumor formation of reactive oxygen and nitrogen species and ameliorating the skewed Th1/Th2 balance in late cancers [37, 40, 80-82]. This ability of phagocytes to infiltrate makes them important in eliminating advanced tumors by phagocytosis and secretion of cytokines for direct or indirect antitumor activities and antibody dependent cell mediated cytotoxicity (ADCC) [83]. Suppression of cell motility and blocking vasculature in tumor microenvironment is a good indicator for inhibition of cancer metastasis and proliferation. Ganoderma lucidum has the potential of suppressing cell motility, inhibiting cell proliferation, inducing apoptosis, and suppressing angiogenesis of highly invasive human breast and prostate cancer cells $[43,44]$. PSK, on the other hand, when injected directly into human stomach tumors prior to surgery is quickly taken up by dendritic cells in and around the tumors, improving the survival and QoL of stomach cancer patients [50]. Thus, PSK has a direct cytotoxic effect on cancer cells. According to Hsu et al. [29], methanol extracts of G. lucidum and G. tsugae inhibit the growth of colorectal cancer cells within $72 \mathrm{hrs}$ by downregulating cyclin A and B1 and upregulating p21 and p27, thereby arresting the cell cycle in G2/M, and thus they 
TABLE 2: Summary of studies on the mechanism of action of mushrooms compounds.

\begin{tabular}{|c|c|c|c|}
\hline Mushroom & Biological activity & Study & Reference \\
\hline \multirow[t]{2}{*}{$\begin{array}{l}\text { Agaricus blazei Murill } \\
\text { (AbM) }\end{array}$} & $\begin{array}{l}\text { Secretion of IL-8, TNF- } \alpha \text {, and NO production by macrophages, } \\
\text { inhibition of cancer cell growth, upregulation of expression and } \\
\text { secretion of anticancer gene and cytokines IL-23, IL-12, IL-1, } \\
\text { MCP-1, G-CSF, and TNF- } \alpha \text {, apoptosis, and NK activation }\end{array}$ & In vitro & {$[25,27,36-40]$} \\
\hline & $\begin{array}{l}\text { Suppress tumor growth and inhibit angiogenesis, stimulate } \\
\text { cytokine and leukocyte growth factors production, amelioration of } \\
\text { skewed Th1/Th2 balance }\end{array}$ & In vivo & {$[26]$} \\
\hline Agaricus bisporus & $\begin{array}{l}\text { Induce apoptosis, inhibit angiogenesis, stimulate TNF- } \alpha \\
\text { production by BMM }\end{array}$ & In vitro & {$[27]$} \\
\hline Ganoderma lucidum & $\begin{array}{l}\text { Cytotoxic to cancer cells, inhibit cancer cell growth, stimulate T } \\
\text { cells, upregulate expression and secretion of IL-1, IL-2, IL-6, } \\
\text { TNF- } \alpha \text {, and IFN } \gamma \text {, suppress cell motility and angiogenesis, inhibit } \\
\text { proliferation and induce apoptosis, downregulate cyclins A and B } \\
\text { and upregulate p21 and p27, arrest cell cycle }\end{array}$ & In vitro & {$[4,14,29,41-44]$} \\
\hline Ganoderma tsugae & $\begin{array}{l}\text { Inhibit cancer cell growth, downregulate cyclins A and B and } \\
\text { upregulate p21 and p27, arrest cell cycle }\end{array}$ & In vitro & {$[29]$} \\
\hline Grifola frondosa & $\begin{array}{c}\text { Activate macrophages, stimulate production of IL-1, IL-6, and IL-8, } \\
\text { stimulate leukocytes }\end{array}$ & In vitro & {$[45-47]$} \\
\hline \multirow[t]{2}{*}{ Sparassis crispa } & $\begin{array}{c}\text { Augment immune system, enhance IL-8 synthesis, activate } \\
\text { leukocytes }\end{array}$ & In vitro & {$[31]$} \\
\hline & Stimulate splenocytes to secrete cytokines & In vivo & [48] \\
\hline \multirow{2}{*}{ Pleurotus tuber-regium } & Stimulate proliferation of NK cells, macrophages, and T cells & In vitro & {$[32-34]$} \\
\hline & $\begin{array}{c}\text { Maturation of lymphocytes, NK cells, and macrophages, increase } \\
\text { weight and size of spleen }\end{array}$ & In vivo & {$[32-34]$} \\
\hline Polyporus rhinoceros & Stimulate proliferation of NK cells, macrophages, and T cells & In vitro & {$[32-34]$} \\
\hline Schizophyllum commune & Prolong life of head/neck/cervical cancer patients & Clinical & {$[30]$} \\
\hline \multirow[t]{2}{*}{ Trametes robiniophila } & $\begin{array}{l}\text { Apoptosis, antiangiogenesis, antimetastasis, drug resistance } \\
\text { reversal, activation of immune system }\end{array}$ & clinical & {$[35]$} \\
\hline & Apoptosis, G0/G1 cell cycle arrest, and Cell damage & In vitro & {$[22]$} \\
\hline \multirow[t]{2}{*}{ Coriolus versicolor } & $\begin{array}{l}\text { Invoke secretion of cytokines IL-1, IL-2, IL-6, IL-8, TNF- } \alpha \text {, and } \\
\text { TNF }\end{array}$ & In vitro & {$[49]$} \\
\hline & Improve survival of stomach cancer patients & Clinical & {$[50]$} \\
\hline Coprinus comatus & Inhibit cancer cell proliferation & In vitro & [51] \\
\hline Pseudallescheria boydii & Stimulate secretion of IL-12 and TNF $\alpha$ & In vivo & {$[52]$} \\
\hline Coprinellus sp. & Inhibit cancer cell proliferation & In vitro & {$[51]$} \\
\hline Lentinula edodes & $\begin{array}{c}\text { Stimulate secretion of IL-1, IL-2, IL-6, IL-8, TNF- } \alpha \text {, and TNF, } \\
\text { cytotoxic and cytostatic to breast cancer cells, inhibit proliferation } \\
\text { cancer cells, inhibit DNA synthesis }\end{array}$ & In vitro & {$[49,53-55]$} \\
\hline Flammulina velutipes & Inhibit cancer cell proliferation & In vitro & [51] \\
\hline
\end{tabular}

are able to suppress tumor growth, induce cell death, and inhibit cell proliferation in human colorectal cancer cells in vivo. Volman et al. [75] confirmed that there is modulation of the immune response of enterocytes, where extracts from mushrooms lower the transactivation of NF-kB in Caco-2 cells, with A. blazei Murill and Coprinus comatus having the pronounced decrease in NF-kB transactivation, which can cause tumor cells to stop proliferating, die, or become sensitive to the action of antitumor agents. In addition, $L$. edodes fruit body water extracts exhibit inhibitory effects on the proliferation of MCF-7 cells and DNA synthesis, indicating that the cytostatic effect of this mushroom extract is much potent on cell cycle of cancer cells [55]. MCF7 cells treated with Huaier (Trametes robiniophila) extract show G0/G1 arrest leading to cell damage and apoptosis [22] and hot water extracts of Coprinellus sp., C. comatus, and Flammulina velutipes have also shown inhibition of cellular proliferation of MCF-7, MDA-MB-231, and BT-20 cells [51].

Suffice it to say, researches have proven that mushrooms compounds exhibit anticancer potential in in vitro, in vivo, and clinical studies as summarized in Table 2. Therefore, critical research on anticancer mushroom compounds is important in the search for new drug discovery. 


\section{Conclusion and Future Perspective}

Bioactive compounds from mushrooms have been shown to activate or modulate the immune system, thereby inhibiting cancer cell metastasis and growth. These compounds work by affecting the maturation, differentiation, and proliferation of immune cells. The major compounds of immune and cancer importance target the gut system, especially intestines as their site of contact and primary action, thereby affecting intestinal immunity and ultimately systemic immunity. These compounds are PAMP and act by interacting with receptors on leucocytes, upregulate genes associated with immunity, increase production of T lymphocytes and cytokines, activate activity of macrophages and cytokines, induce apoptosis, affect cell cycle, and increase infiltration of cytotoxic T cells in tumors. Critical studies on the mechanism of action and development of anticancer agents from mushrooms are very important so as to reduce the burden of cancer and improve quality of life of cancer patients.

Research, therefore, which targets modulation of the immune system to fight cancer, especially from mushroom compounds, is important. Future perspective should therefore be directed towards finding out the molecular mechanisms of different mushroom compounds in cancer immunotherapy and encouraging consumption of mushroom and other natural plant materials due to their holistic treatment. Further studies should be carried out on conservation of biodiversity of mushrooms, and critical analysis should be done to evaluate and compare the pharmacological importance and mushrooms of different regions.

\section{Conflicts of Interest}

The author declares that there are no conflicts of interest regarding the publication of this paper.

\section{Acknowledgments}

The author is grateful to Egerton University for granting the opportunity to work and time to publish. He also extends his appreciation to Professor YuHong Bian from Tianjin University of Traditional Chinese Medicine, China, for her mentorship.

\section{References}

[1] J. Ferlay, H. R. Shin, F. Bray, D. Forman, C. Mathers, and D. M. Parkin, "Estimates of worldwide burden of cancer in 2008: GLOBOCAN 2008," International Journal of Cancer, vol. 127, no. 12, pp. 2893-2917, 2010.

[2] L. A. Torre, F. Bray, R. L. Siegel, J. Ferlay, and J. LortetTieulent, "Global cancer statistics, 2012," CA: A Cancer Journal for Clinicians, vol. 65, no. 2, pp. 87-108, 2015.

[3] Global Burden of Disease Cancer Collaboration, "Novel Methods for Measuring Global Cancer Burden," JAMA Oncology, vol. 1, no. 4, pp. 505-527, 2015.

[4] H.-S. Chen, Y.-F. Tsai, S. Lin et al., "Studies on the immunomodulating and anti-tumor activities of Ganoderma lucidum (Reishi) polysaccharides," Bioorganic \& Medicinal Chemistry, vol. 12, no. 21, pp. 5595-5601, 2004.
[5] P. M. Kidd, "The use of mushroom glucans and proteoglycans in cancer treatment," Alternative Medicine Review, vol. 5, no. 1, pp. 4-27, 2000.

[6] A. T. Borchers, A. Krishnamurthy, C. L. Keen, F. J. Meyers, and M. E. Gershwin, "The immunobiology of mushrooms," Experimental Biology and Medicine, vol. 233, no. 3, pp. 259-276, 2008.

[7] G. D. Brown, J. Herre, D. L. Williams, J. A. Willment, A. S. J. Marshall, and S. Gordon, "Dectin-1 mediates the biological effects of $\beta$-glucans," The Journal of Experimental Medicine, vol. 197, no. 9, pp. 1119-1124, 2003.

[8] C. Lull, H. J. Wichers, and H. F. J. Savelkoul, "Antiinflammatory and immunomodulating properties of fungal metabolites," Mediators of Inflammation, vol. 2005, no. 2, pp. 63-80, 2005.

[9] J. Chen and R. Seviour, "Medicinal importance of fungal $\beta$ -

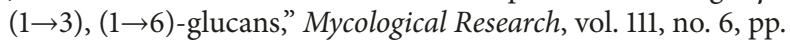
635-652, 2007.

[10] V. Vetvicka, A. Vashishta, S. Saraswat-Ohri, and J. Vetvickova, "Immunological effects of yeast- and mushroom-derived $\beta$ glucans," Journal of Medicinal Food, vol. 11, no. 4, pp. 615-622, 2008.

[11] FS. Reis, A. Martins, MH. Vasconcelos, P. Morales, and Ferreira., "ICFR: Functional foods based on extracts or compounds derived from mushrooms," Trends in Food Science \& Technology, vol. 66, pp. 48-62, 2017.

[12] V. E. C. Ooi and F. Liu, "Immunomodulation and anti-cancer activity of polysaccharide-protein complexes," Current Medicinal Chemistry, vol. 7, no. 7, pp. 715-729, 2000.

[13] A. T. Borchers, C. L. Keen, and M. E. Gershwini, "Mushrooms, Tumors, and Immunity: An Update," Experimental Biology and Medicine, vol. 229, no. 5, pp. 393-406, 2004.

[14] B.-S. Min, J.-J. Gao, N. Nakamura, and M. Hattori, “Triterpenes from the spores of Ganoderma lucidum and their cytotoxicity against Meth-A and LLC tumor cells," Chemical \& Pharmaceutical Bulletin, vol. 48, no. 7, pp. 1026-1033, 2000.

[15] K. R. Martin and S. K. Brophy, "Commonly consumed and specialty dietary mushrooms reduce cellular proliferation in MCF-7 human breast cancer cells," Experimental Biology and Medicine, vol. 235, no. 11, pp. 1306-1314, 2010.

[16] T. Ikekawa, "Beneficial Effects of Edible and Medicinal Mushrooms on Health Care," International Journal of Medicinal Mushrooms, vol. 3, no. 4, p. 2, 2001.

[17] S. P. Wasser, "Medicinal mushrooms as a source of antitumor and immunomodulating polysaccharides," Applied Microbiology and Biotechnology, vol. 60, no. 3, pp. 258-274, 2002.

[18] R. P. Pelley and F. M. Strickland, "Plants, polysaccharides, and the treatment and prevention of neoplasia," Critical Reviews in Oncogenesis, vol. 11, no. 3-4, pp. 189-225, 2000.

[19] S. Baldassano, G. Accardi, and S. Vasto, "Beta-glucans and cancer: The influence of inflammation and gut peptide," European Journal of Medicinal Chemistry, vol. 142, pp. 486-492, 2017.

[20] S.-N. Chen, C.-S. Chang, M.-H. Hung et al., "The effect of mushroom beta-glucans from solid culture of ganoderma lucidum on inhibition of the primary tumor metastasis," Evidence-Based Complementary and Alternative Medicine, vol. 2014, Article ID 252171, 2014.

[21] Y. Gao and S. Zhou, "The Immunomodulating Effects of Ganoderma lucidum (Curt.: Fr.) P. Karst. (Ling Zhi, Reishi Mushroom) (Aphyllophoromycetideae)," International Journal of Medicinal Mushrooms, vol. 4, no. 1, 2002. 
[22] I. Sarangi, D. Ghosh, S. K. Bhutia, S. K. Mallick, and T. K. Maiti, "Anti-tumor and immunomodulating effects of Pleurotus ostreatus mycelia-derived proteoglycans," International Immunopharmacology, vol. 6, no. 8, pp. 1287-1297, 2006.

[23] F. Hong, J. Yan, J. T. Baran et al., "Mechanism by which orally administered $\beta$-1,3-glucans enhance the tumoricidal activity of antitumor monoclonal antibodies in murine tumor models," The Journal of Immunology, vol. 173, no. 2, pp. 797-806, 2004.

[24] T. Mizuno, "Medicinal Properties and Clinical Effects of Culinary-Medicinal Mushroom Agaricus blazei Murrill (Agaricomycetideae) (Review)," International Journal of Medicinal Mushrooms, vol. 4, no. 4, 14 pages, 2002.

[25] K. Sorimachi, K. Akimoto, Y. Ikehara, K. Inafuku, A. Okubo, and S. Yamazaki, "Secretion of TNF- $\alpha$, IL- 8 and nitric oxide by macrophages activated with Agaricus blazei Murill fractions in vitro," Cell Structure and Function, vol. 26, no. 2, pp. 103-108, 2001.

[26] Y. C. Niu, J.-C. Liu, X. M. Zhao, and X. X. Wu, "A low molecular weight polysaccharide isolated from Agaricus blazei suppresses tumor growth and angiogenesis in vivo," Oncology Reports, vol. 21, no. 1, pp. 145-152, 2009.

[27] M. Endo, H. Beppu, H. Akiyama et al., "Agaritine purified from Agaricus blazei Murrill exerts anti-tumor activity against leukemic cells," Biochimica et Biophysica Acta (BBA) - General Subjects, vol. 1800, no. 7, pp. 669-673, 2010.

[28] T. Takaku, Y. Kimura, and H. Okuda, "Isolation of an antitumor compound from Agaricus blazei Murill and its mechanism of action," Journal of Nutrition, vol. 131, no. 5, pp. 1409-1413, 2001.

[29] S.-C. Hsu, C.-C. Ou, J.-W. Li et al., "Ganoderma tsugae extracts inhibit colorectal cancer cell growth via $\mathrm{G}_{2} / \mathrm{M}$ cell cycle arrest," Journal of Ethnopharmacology, vol. 120, no. 3, pp. 394-401, 2008.

[30] A. T. Borchers, J. S. Stern, R. M. Hackman, C. L. Keen, and M. E. Gershwin, "Mushrooms, tumors, and immunity," Proceedings of the Society for Experimental Biology and Medicine, vol. 221, no. 4, pp. 281-293, 1999.

[31] S. Nameda, T. Harada, N. N. Miura et al., "Enhanced cytokine synthesis of leukocytes by a $\beta$-glucan preparation, SCG, extracted from a medicinal mushroom, Sparassis crispa," Immunopharmacology and Immunotoxicology, vol. 25, no. 3, pp. 321-335, 2003.

[32] K.-H. Wong, C. K. M. Lai, and P. C. K. Cheung, "Immunomodulatory activities of mushroom sclerotial polysaccharides," Food Hydrocolloids, vol. 25, no. 2, pp. 150-158, 2011.

[33] Lai KMC, Antitumor Effects of Polysaccharides Extracted from Mushroom Sclerotia: An in Vitro and in Vivo Study, Chinese University of Hong Kong, Hong Kong, China, 2005.

[34] M. Zhang, L. Zhang, P. C. K. Cheung, and V. E. C. Ooi, "Molecular weight and anti-tumor activity of the water-soluble polysaccharides isolated by hot water and ultrasonic treatment from the sclerotia and mycelia of Pleurotus tuber-regium," Carbohydrate Polymers, vol. 56, no. 2, pp. 123-128, 2004.

[35] L. Li and Y. Wang, "Progress on Experimental Research and Clinical Application of Trametes Robiniophila," China Cancer, vol. 16, pp. 110-113, 2006.

[36] D. T. Førland, E. Johnson, A. M. A. Tryggestad, T. Lyberg, and G. Hetland, "An extract based on the medicinal mushroom Agaricus blazei Murill stimulates monocyte-derived dendritic cells to cytokine and chemokine production in vitro," Cytokine, vol. 49, no. 3, pp. 245-250, 2010.

[37] H. Takimoto, H. Kato, M. Kaneko, and Y. Kumazawa, "Amelioration of skewed Th1/Th2 balance in tumor-bearing and asthma-induced mice by oral administration of Agaricus blazei extracts," Immunopharmacology and Immunotoxicology, vol. 30, no. 4, pp. 747-760, 2008.

[38] Y. Fujimiya, Y. Suzuki, K.-I. Oshiman et al., "Selective tumoricidal effect of soluble proteoglucan extracted from the basidiomycete, Agaricus blazei Murill, mediated via natural killer cell activation and apoptosis," Cancer Immunology, Immunotherapy, vol. 46, no. 3, pp. 147-159, 1998.

[39] B. Grinde, G. Hetland, and E. Johnson, "Effects on gene expression and viral load of a medicinal extract from Agaricus blazei in patients with chronic hepatitis $\mathrm{C}$ infection," International Immunopharmacology, vol. 6, no. 8, pp. 1311-1314, 2006.

[40] E. Johnson, D. T. Førland, L. Sætre, S. V. Bernardshaw, T. Lyberg, and G. Hetland, "Effect of an extract based on the medicinal mushroom agaricus blazei murill on release of cytokines, chemokines and leukocyte growth factors in human blood ex vivo and in vivo," Scandinavian Journal of Immunology, vol. 69, no. 3, pp. 242-250, 2009.

[41] C. M. Chien, J.-L. Cheng, W.-T. Chang et al., "Polysaccharides of Ganoderma lucidum alter cell immunophenotypic expression and enhance CD56 + NK-cell cytotoxicity in cord blood," Bioorganic \& Medicinal Chemistry, vol. 12, no. 21, pp. 56035609, 2004.

[42] S.-Y. Wang, M.-L. Hsu, H.-C. Hsu et al., "The anti-tumor effect of Ganoderma lucidum is mediated by cytokines released from activated macrophages and T lymphocytes," International Journal of Cancer, vol. 70, no. 6, pp. 699-705, 1997.

[43] H. Hu, N.-S. Ahn, X. Yang, Y.-S. Lee, and K.-S. Kang, "Ganoderma lucidum extract induces cell cycle arrest and apoptosis in MCF-7 human breast cancer cell," International Journal of Cancer, vol. 102, no. 3, pp. 250-253, 2002.

[44] G. Stanley, K. Harvey, V. Slivova, J. Jiang, and D. Sliva, “Ganoderma lucidum suppresses angiogenesis through the inhibition of secretion of VEGF and TGF- $\beta 1$ from prostate cancer cells," Biochemical and Biophysical Research Communications, vol. 330, no. 1, pp. 46-52, 2005.

[45] G. Hetland, M. Løvik, and H. G. Wiker, "Protective effect of $\beta$ glucan against Mycobacterium bovis, BCG infection in BALB/c mice," Scandinavian Journal of Immunology, vol. 47, no. 6, pp. 548-553, 1998.

[46] V. Manohar, N. A. Talpur, B. W. Echard, S. Lieberman, and H. G. Preuss, "Effects of a water-soluble extract of maitake mushroom on circulating glucose/insulin concentrations in KK mice," Diabetes, Obesity and Metabolism, vol. 4, no. 1, pp. 43-48, 2002.

[47] T. Harada, N. Miura, Y. Adachi, M. Nakajima, T. Yadomae, and N. Ohno, "Effect of SCG, 1,3- $\beta$-D-Glucan from Sparassis crispa on the hematopoietic response in cyclophosphamide induced leukopenic mice," Biological \& Pharmaceutical Bulletin, vol. 25, no. 7, pp. 931-939, 2002.

[48] T. Harada and N. Ohno, "Contribution of dectin-1 and granulocyte macrophage-colony stimulating factor (GM-CSF) to immunomodulating actions of $\beta$-glucan," International Immunopharmacology, vol. 8, no. 4, pp. 556-566, 2008.

[49] S. P. Wasser and A. L. Weis, "Medicinal properties of substances occurring in higher Basidiomycetes mushrooms: current prespectives," International Journal of Medicinal Mushrooms, vol. 1, pp. 31-62, 1999.

[50] S. Tsujitani, Y. Kakeji, H. Orita et al., "Postoperative adjuvant immunochemotherapy and infiltration of dendritic cells for patients with advanced gastric cancer," Anticancer Reseach, vol. 12, no. 3, pp. 645-648, 1992. 
[51] T. Ikekawa, "Beneficial Effects of Edible and Medicinal Mushrooms on Health Care," International Journal of Medicinal Mushrooms, vol. 3, no. 4, 2001.

[52] V. C. B. Bittencourt, R. T. Figueiredo, R. B. Da Silva et al., "An $\alpha$-glucan of Pseudallescheria boydii is involved in fungal phagocytosis and toll-like receptor activation," The Journal of Biological Chemistry, vol. 281, no. 32, pp. 22614-22623, 2006.

[53] S.-J. Wu, J.-Y. Tsai, M.-N. Lai, and L.-T. Ng, "Armillariella mellea shows anti-inflammatory activity by inhibiting the expression of NO, iNOS, COX-2 and cytokines in THP-1 cells," American Journal of Chinese Medicine, vol. 35, no. 3, pp. 507-516, 2007.

[54] Dembitsky V. M. and G. A. Tolstikov, "Halogenated phenol compounds in lichens and fungi," Chemistry for Sustainable Development, vol. 11, pp. 557-565, 2003.

[55] C. Israilides, D. Kletsas, D. Arapoglou et al., "In vitro cytostatic and immunomodulatory properties of the medicinal mushroom Lentinula edodes," Phytomedicine, vol. 15, no. 6-7, pp. 512519, 2008.

[56] M. S. Lee and Y.-J. Kim, "Signaling pathways downstream of pattern-recognition receptors and their cross talk," Annual Review of Biochemistry, vol. 76, pp. 447-480, 2007.

[57] P. R. Taylor, G. D. Brown, D. M. Reid et al., “The $\beta$-glucan receptor, dectin-1, is predominantly expressed on the surface of cells of the monocyte/macrophage and neutrophil lineages," The Journal of Immunology, vol. 169, no. 7, pp. 3876-3882, 2002.

[58] G. D. Brown and S. Gordon, "A new receptor for $\beta$-glucans," Nature, vol. 413, no. 6851, pp. 36-37, 2001.

[59] S. Xu, J. Huo, K.-G. Lee, T. Kurosaki, and K.-P. Lam, "Phospholipase $\mathrm{C} \gamma 2$ is critical for Dectin-1-mediated Ca2+ flux and cytokine production in dendritic cells," The Journal of Biological Chemistry, vol. 284, no. 11, pp. 7038-7046, 2009.

[60] S. Dillon, S. Agrawal, K. Banerjee et al., "Yeast zymosan, a stimulus for TLR2 and dectin-1, induces regulatory antigenpresenting cells and immunological tolerance," The Journal of Clinical Investigation, vol. 116, no. 4, pp. 916-928, 2006.

[61] J. K. Czop, N. M. Valiante, and M. J. Janusz, "Phagocytosis of particulate activators of the human alternative complement pathway through monocyte beta-glucan receptors.," Progress in Clinical and Biological Research, vol. 297, pp. 287-296, 1989.

[62] A. Roeder, C. J. Kirschning, R. A. Rupec, M. Schaller, G. Weindl, and H. C. Korting, "Toll-like receptors as key mediators in innate antifungal immunity," Medical Mycology, vol. 42, no. 6, pp. 485-498, 2004.

[63] B. N. Gantner, R. M. Simmons, S. J. Canavera, S. Akira, and D. M. Underhill, "Collaborative induction of inflammatory responses by dectin-1 and toll-like receptor 2," The Journal of Experimental Medicine, vol. 197, no. 9, pp. 1107-1117, 2003.

[64] H. S. Goodridge, A. J. Wolf, and D. M. Underhill, "Beta-glucan recognition by the innate immune system," Immunological Reviews, vol. 230, no. 1, pp. 38-50, 2009.

[65] Y. Kumagai and S. Akira, "Identification and functions of pattern-recognition receptors," The Journal of Allergy and Clinical Immunology, vol. 125, no. 5, pp. 985-992, 2010.

[66] H. Itoh, H. Ito, H. Amano, and H. Noda, "Inhibitory action of a $(1 \rightarrow 6)-\beta$-D-glucan-protein complex (F III-2-b) isolated from Agaricus blazei Murill ("Himematsutake") on Meth A fibrosarcoma-bearing mice and its antitumor mechanism," The Japanese Journal of Pharmacology, vol. 66, no. 2, pp. 265-271, 1994.

[67] S. Bernardshaw, T. Lyberg, G. Hetland, and E. Johnson, "Effect of an extract of the mushroom Agaricus blazei Murill on expression of adhesion molecules and production of reactive oxygen species in monocytes and granulocytes in human whole blood ex vivo," APMIS-Acta Pathologica, Microbiologica et Immunologica Scandinavica, vol. 115, no. 6, pp. 719-725, 2007.

[68] T. Okamoto, R. Kodoi, Y. Nonaka et al., "Lentinan from shiitake mushroom (Lentinus edodes) suppresses expression of cytochrome P450 1A subfamily in the mouse liver," BioFactors, vol. 21, no. 1-4, pp. 407-409, 2004.

[69] N. Ohno, N. N. Miura, N. Chiba, Y. Adachi, and T. Yadomae, "Comparison of the Immunopharmacological Activities of Triple and Single-Helical Schizophyllan in Mice," Biological \& Pharmaceutical Bulletin, vol. 18, no. 9, pp. 1242-1247, 1995.

[70] R. H. P. Wilbers, L. B. Westerhof, J. Van de Velde et al., "Physical interaction of $\mathrm{T}$ cells with dendritic cells is not required for the immunomodulatory effects of the edible mushroom agaricus subrufescens," Frontiers in Immunology, vol. 7, article no. 519, 2016.

[71] T. Yadomae, "Structure and biological activities of fungal $\beta$-1,3glucans," Yakugaku Zasshi, vol. 120, no. 5, pp. 413-431, 2000.

[72] J. A. Bohn and J. N. BeMiller, " $(1 \rightarrow 3)-\beta$-D-glucans as biological response modifiers: a review of structure-functional activity relationships," Carbohydrate Polymers, vol. 28, no. 1, pp. 3-14, 1995.

[73] P. A. Ayeka, Y. Bian, P. G. Mwitari et al., "Immunomodulatory and anticancer potential of Gan cao (Glycyrrhiza uralensis Fisch.) polysaccharides by CT-26 colon carcinoma cell growth inhibition and cytokine IL-7 upregulation in vitro," $B M C$ Complementary and Alternative Medicine, vol. 16, no. 1, article no. 206, 2016.

[74] P. A. Ayeka, Y. Bian, P. M. Githaiga, and Y. Zhao, "The immunomodulatory activities of licorice polysaccharides (Glycyrrhiza uralensis Fisch.) in CT 26 tumor-bearing mice," BMC Complementary and Alternative Medicine, vol. 17, no. 1, article no. 536, 2017.

[75] J. J. Volman, R. P. Mensink, J. D. Ramakers et al., "Dietary $(1 \rightarrow 3),(1 \rightarrow 4)-\beta$-d-glucans from oat activate nuclear factor- $\kappa \mathrm{B}$ in intestinal leukocytes and enterocytes from mice," Nutrition Research, vol. 30, no. 1, pp. 40-48, 2010.

[76] Y. Adachi, M. Okazaki, N. Ohno, and T. Yadomae, "Enhancement of Cytokine Production by Macrophages Stimulated with $(1 \rightarrow 3)-\beta$-D-Glucan, Grifolan (GRN), Isolated from Grifola frondosa," Biological \& Pharmaceutical Bulletin, vol. 17, no. 12, pp. 1554-1560, 1994.

[77] Y.-L. Lin, S.-S. Lee, S.-M. Hou, and B.-L. Chiang, "Polysaccharide purified from Ganoderma lucidum induces gene expression changes in human dendritic cells and promotes $\mathrm{T}$ helper 1 immune response in BALB/c mice," Molecular Pharmacology, vol. 70, no. 2, pp. 637-644, 2006.

[78] T. Harada, S. Masuda, M. Arii et al., "Soy isoflavone aglycone modulates A hematopoietic response in combination with soluble $\beta$-glucan: SCG, Biological \& Pharmaceutical Bulletin, vol. 28, no. 12, pp. 2342-2345, 2005.

[79] K. Murakawa, K. Fukunaga, M. Tanouchi, M. Hosokawa, Z. Hossain, and K. Takahashi, "Therapy of myeloma in vivo using marine phospholipid in combination with Agaricus blazei Murill as an immune respond activator," Journal of Oleo Science, vol. 56, no. 4, pp. 179-188, 2007.

[80] Y. Yazawa, M. Yokota, and K. Sugiyama, "Antitumor promoting effect of an active component of polyporus, ergosterol and related compounds on rat urinary bladder carcinogenesis in a short-term test with concanavalin A," Biological \& Pharmaceutical Bulletin, vol. 23, no. 11, pp. 1298-1302, 2000. 
[81] D. T. Førland, E. Johnson, L. Sætre, T. Lyberg, I. Lygren, and G. Hetland, "Effect of an extract based on the medicinal mushroom Agaricus blazei Murill on expression of cytokines and calprotectin in patients with ulcerative colitis and Crohn's disease," Scandinavian Journal of Immunology, vol. 73, no. 1, pp. 66-75, 2011.

[82] A. Viola, "345 Improving cancer immunotherapy by preventing chemokine nitration," European Journal of Cancer Supplements, vol. 8, no. 5, p. 89, 2010.

[83] E. Di Carlo, G. Forni, P. Lollini, M. P. Colombo, A. Modesti, and P. Musiani, "The intriguing role of polymorphonuclear neutrophils in antitumor reactions," Blood, vol. 97, no. 2, pp. 339-345, 2001. 


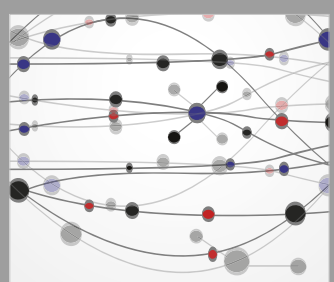

The Scientific World Journal
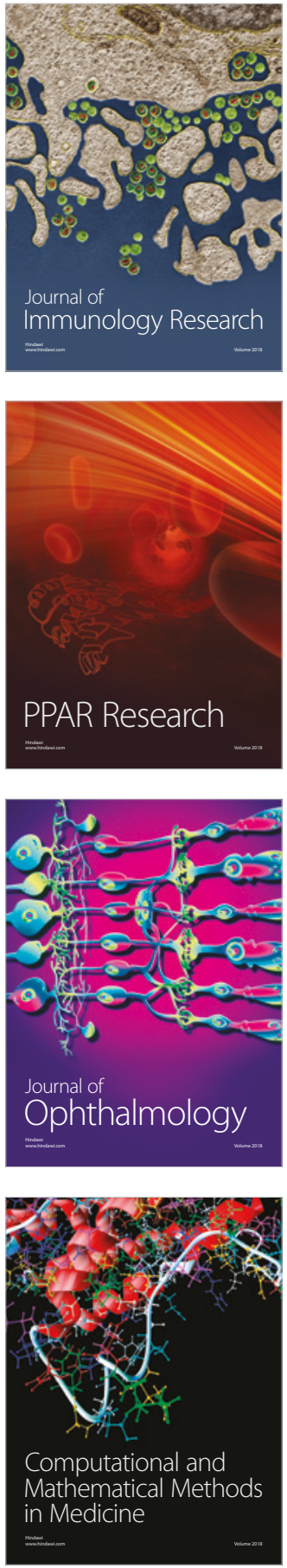

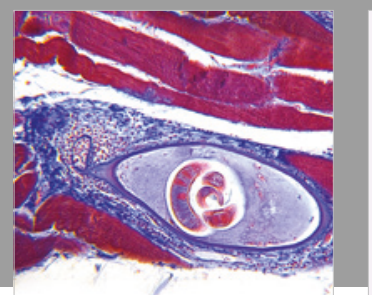

Gastroenterology Research and Practice

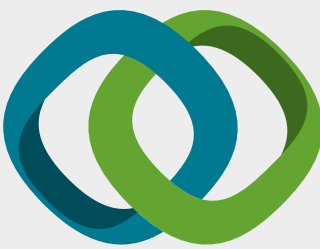

\section{Hindawi}

Submit your manuscripts at

www.hindawi.com
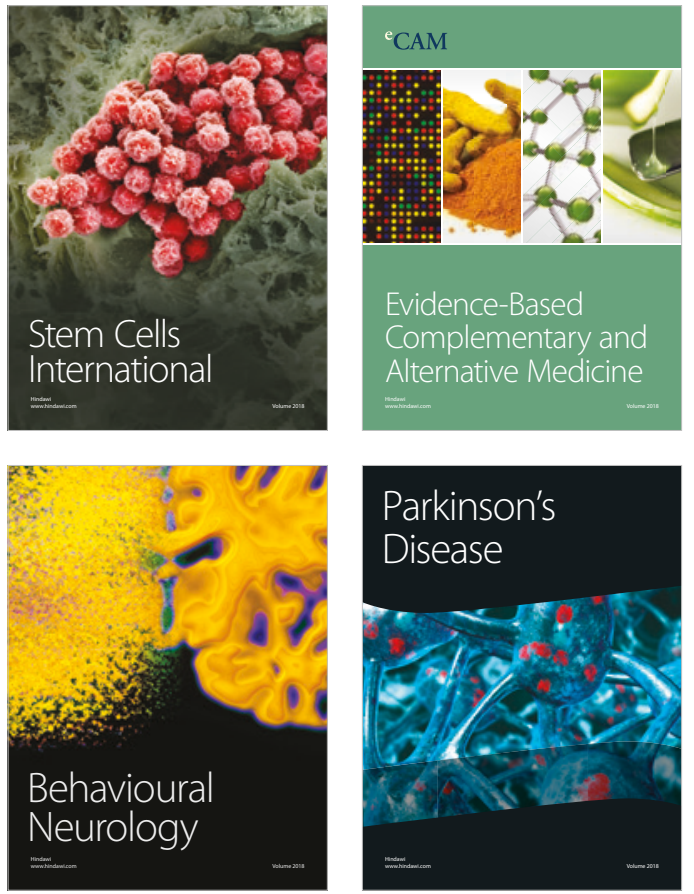

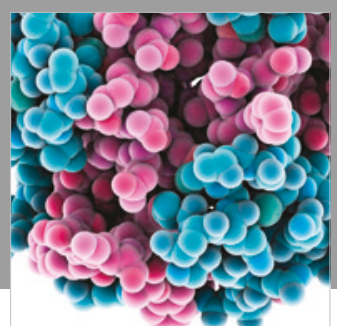

ournal of

Diabetes Research

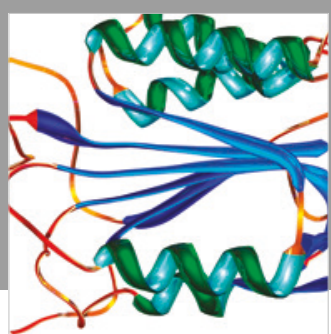

Disease Markers
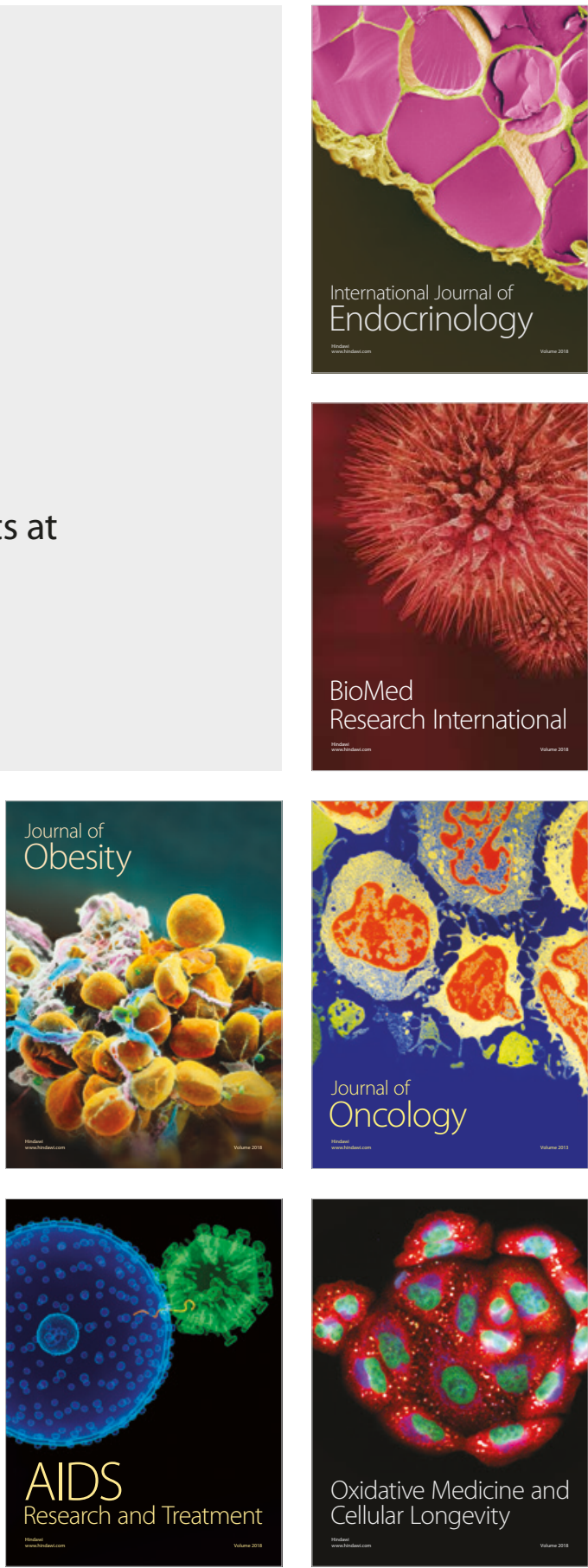